\title{
Efficacy Estimates for Various COVID-19 Vaccines: What we Know from the Literature and Reports
}

\author{
Julia Shapiro $^{1}$, Natalie E. Dean ${ }^{1}$, Zachary J. Madewell ${ }^{1}$, Yang Yang ${ }^{1}$, M.Elizabeth Halloran ${ }^{2,}{ }^{3}$, \\ and Ira Longini ${ }^{*}$ \\ ${ }^{1}$ Department of Biostatistics, University of Florida, Gainesville, FL, USA \\ ${ }^{2}$ Vaccine and Infectious Diseases Division, Fred Hutchinson Cancer Center, Seattle, WA, USA \\ ${ }^{3}$ Department of Biostatistics, University of Washington, Seattle, WA, USA \\ ${ }^{*}$ address correspondence to Ira Longini at ilongini@ufl.edu
}

June 17, 2021

\section{Abstract}

In this report, we provide summary estimates, from publications and reports, of vaccine efficacy (VE) for the COVID-19 vaccines that are being rolled out on a global scale. We find that, on average, the efficacy against any disease with infection is 85\% (95\% CI: 71 - 93\%) after a fully course of vaccination. The VE against severe disease, hospitalization or death averages close to $100 \%$. The average VE against infection, regardless of symptoms, is $84 \%$ (95\% CI: $70-91 \%)$. We also find that the average VE against transmission to others for infected vaccinated people is $48 \%$ (95\% CI: 45 - 52\%). Finally, we prove summary estimates of the VE against any disease with infection for some of the variants of concern (VOC). The average VE for the VOC $\gamma(\mathrm{P} 1)$ is $61 \%$ (95\% CI: 43 - 73\%). The average VE for the VOC $\alpha$ (B.1.1.7), $\beta$ (B.1.351), and $\delta$ (B.1.617.2) after dose 1 are 48\% (95\% CI: $44-51 \%$ ), 35\% (95\% CI: $-11-62 \%)$, and 33\% (95\% CI: $21-43 \%)$, respectively. The average VE for the VOC $\alpha$ (B.1.1.7), $\beta$ (B.1.351), and $\delta$ (B.1.617.2) after dose 2 are 85\% (95\% CI: $25-97 \%$ ), $57 \%$ (95\% CI: $14-78 \%$ ), and 78\% (95\% CI: $28-93 \%)$, respectively. 
medRxiv preprint doi: https://doi.org/10.1101/2021.05.20.21257461; this version posted June 18, 2021. The copyright holder for this preprint (which was not certified by peer review) is the author/funder, who has granted medRxiv a license to display the preprint in perpetuity.

It is made available under a CC-BY 4.0 International license.

\section{Introduction}

In this report, we summarize estimates of vaccine efficacy (VE) for the COVID-19 vaccines that are being rolled out on local and global scales. This includes the Pfizer, Moderna, Johnson \& Johnson, AstraZeneca, Sputnik, Novavax, Sinovac, and Sinopharm vaccines. VE estimates are taken from journal articles and media reports for the vaccines that have gone through double-blinded, placebo-controlled, phase III vaccine trials, as well as observational studies. Some of the estimates are based on rigorous, preplanned statistical analyses from double-blinded, placebo-controlled trials, while others are extracted from observational studies with different levels of control. These studies are reported from a variety of sources including publications, reports, and sometimes press releases. Because of this, we do not carry out a formal meta analysis. In all cases, we try to extract estimates for one or more of the triplet of vaccine efficacy parameters $\left(V E_{S}, V E_{P}, V E_{I}\right)[1]$, where $V E_{S}$ is $\mathrm{VE}$ against infection; $V E_{P}$ is $\mathrm{VE}$ against disease, given infection; and $V E_{I}$ is $\mathrm{VE}$ against transmission to others, given infection. A fourth parameter, $V E_{S P}$, which is $\mathrm{VE}$ against disease and infection, tends to be available from vaccine trials, and it is the usual primary outcome for those trials (i.e., cases of disease that are confirmed infections). The $V E_{S P}$ is a function of both the $V E_{S}$ and $V E_{P}$. If we believe in a multiplicative and independent relationship, then $V E_{S P}=1-\left(1-V E_{S}\right)\left(1-V E_{P}\right)$. Thus, if we have two of these VE's, we can always calculate the third.

In the material that follows, we give estimates of these VE's as a function of time when protection is believed to begin to occur after the first and second dose for two-dose vaccines, and after the first dose for one-dose vaccines. We also provide $V E_{S P}$ estimates for protection against the variants of concern (VOC) $\gamma(\mathrm{P} 1), \alpha$ (B.1.1.7), $\beta$ (B.1.351), and $\delta$ (B.1.617.2). The methods for creating the forest plots are given in the Appendix. The supporting tables for the analysis are also given in the Appendix. Not all estimates described in the tables are given in the figures, as we have tried to extract the essential information without getting lost in too much detail. However, virtually all the complete information is given in the Appendix tables.

\section{Results}

We first consider VE for the original wild type viruses. Figure 1 (Table A1) give the estimates of the $V E_{S P}$ after the second dose for two-dose vaccines. All the estimates are from doubleblinded, placebo-controlled vaccine trials. With the exception of the Sinovac vaccine, they are all over $80 \%$, with a summary estimate of $85 \%(95 \%$ CI: $71-93 \%)$. The Sinovac $V E_{S P}$ estimate is $51 \%$ (95\% CI: $36-62 \%)$. 
medRxiv preprint doi: https://doi.org/10.1101/2021.05.20.21257461; this version posted June 18, 2021. The copyright holder for this preprint (which was not certified by peer review) is the author/funder, who has granted medRxiv a license to display the preprint in perpetuity.

It is made available under a CC-BY 4.0 International license .

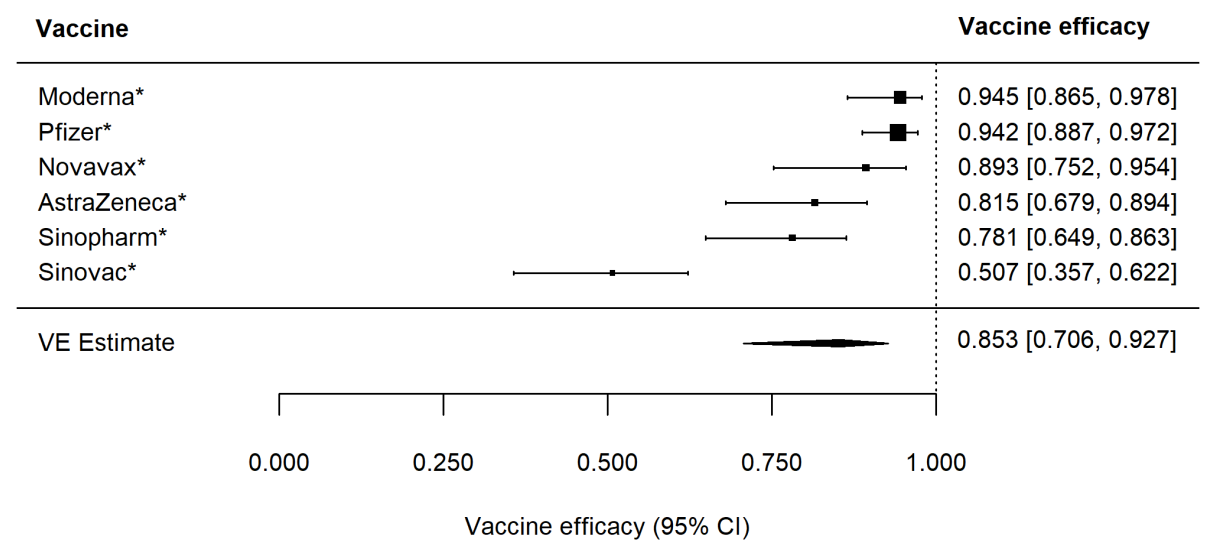

Figure 1: Forest plot of vaccine efficacy to prevent any disease after dose 2, $\boldsymbol{V} \boldsymbol{E}_{\boldsymbol{S P}} .{ }^{*}$ indicates double-blinded, randomized vaccine trial.

The estimated $V E_{S P}$ after one dose, for both two-dose and one-dose vaccines, is given in Figure 2 (Table A2), where the Johnson \& Johnson vaccine is the only one-dose vaccine listed. The estimates are generally almost as high as protection after one dose, with summary estimated of $82 \%$ (95\% CI: $72-88 \%)$.

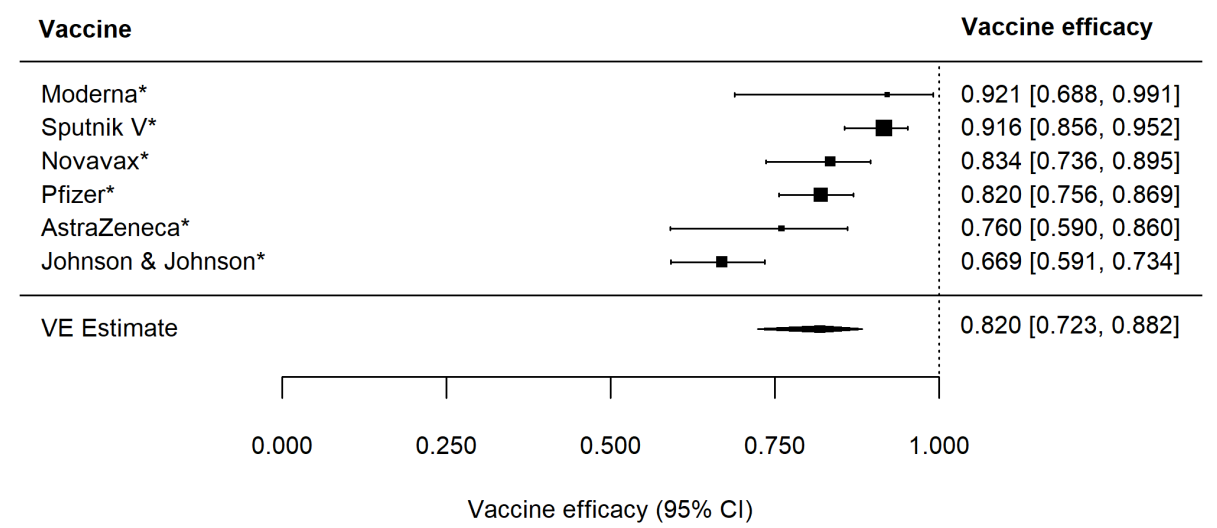

Figure 2: Forest plot of vaccine efficacy to prevent any disease after dose 1, $\boldsymbol{V} \boldsymbol{E}_{\boldsymbol{S P}} .{ }^{*}$ indicates double-blinded, randomized vaccine trial. 
medRxiv preprint doi: https://doi.org/10.1101/2021.05.20.21257461; this version posted June 18, 2021. The copyright holder for this preprint (which was not certified by peer review) is the author/funder, who has granted medRxiv a license to display the preprint in perpetuity.

It is made available under a CC-BY 4.0 International license.

Figure 3 (Table A3) give the estimates of the $V E_{S P}^{S}$ (VE for severe disease with infection) after the second dose for two-dose vaccines. The estimates a very high, and generally close to $100 \%$, with relatively poor precision.

\begin{tabular}{|c|c|c|c|c|}
\hline Vaccine & & & & Vaccine efficacy \\
\hline AstraZeneca* & & & & -1.000 [Cl not reported] \\
\hline Moderna* & & & & -1.000 [Cl not reported] \\
\hline Novavax* & & & & 1.000 [Cl not reported] \\
\hline Sinovac* & & & & $1.000[0.534,1.000]$ \\
\hline Pfizer & & & & $0.920[0.750,1.000]$ \\
\hline$\Gamma$ & $T$ & $T$ & $T$ & 7 \\
\hline 0.000 & 0.250 & 0.500 & 0.750 & 1.000 \\
\hline
\end{tabular}

Figure 3: Forest plot of vaccine efficacy to prevent severe disease after dose $2, \boldsymbol{V} \boldsymbol{E}_{\boldsymbol{S P}}^{S}$. * indicates double-blinded, randomized vaccine trial. 
medRxiv preprint doi: https://doi.org/10.1101/2021.05.20.21257461; this version posted June 18, 2021. The copyright holder for this preprint (which was not certified by peer review) is the author/funder, who has granted medRxiv a license to display the preprint in perpetuity.

It is made available under a CC-BY 4.0 International license .

Figure 4 (Table A4) give the estimates of the $V E_{S P}^{S}$ (VE for severe disease with infection) after the first dose for two-dose vaccines and one dose for the one-dose vaccine. The summary estimated is quite high at $86 \%$ (95\% CI: 39 - 97\%).

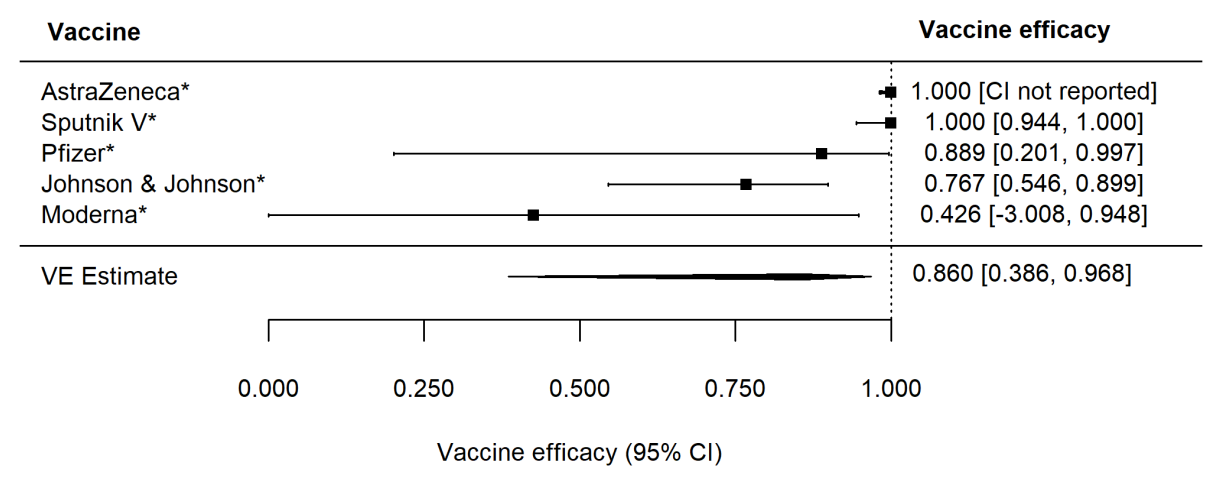

Figure 4: Forest plot of vaccine efficacy to prevent severe disease after dose $\mathbf{1}, \boldsymbol{V} \boldsymbol{E}_{\boldsymbol{S P}}^{S}$. * indicates double-blinded, randomized vaccine trial.

VE against hospitalization and death were quite high, as shown in Figures 5 and 6 (Tables A5 and A6).

\begin{tabular}{|c|c|c|c|c|}
\hline \multicolumn{4}{|l|}{ Vaccine } & Vaccine efficacy \\
\hline \multicolumn{4}{|l|}{ AstraZeneca* } & 1.000 [Cl not reported] \\
\hline \multicolumn{4}{|l|}{ Novavax* } & $-1.000[\mathrm{Cl}$ not reported] \\
\hline \multicolumn{4}{|l|}{ Johnson \& Johnson* } & 一 $\quad 0.931[0.727,0.992]$ \\
\hline \multicolumn{4}{|l|}{ Moderna } & $0.890[0.130,0.990]$ \\
\hline \multicolumn{4}{|l|}{ Pfizer } & $0.870[0.550,1.000]$ \\
\hline \multicolumn{4}{|l|}{ Sinovac* } & $0.837[0.580,0.937]$ \\
\hline \multicolumn{4}{|l|}{ Sinopharm } & $0.787[0.260,0.939]$ \\
\hline \multirow[t]{2}{*}{ VE Estimate } & & & $\ldots$ & $0.850[0.708,0.922]$ \\
\hline & $T$ & $T$ & $T$ & 7 \\
\hline 0.000 & 0.250 & 0.500 & 0.750 & 1.000 \\
\hline
\end{tabular}

Figure 5: Forest plot of vaccine efficacy to prevent hospitalization, $\boldsymbol{V} \boldsymbol{E}_{\boldsymbol{S} \boldsymbol{P}}^{\boldsymbol{H}}$. ${ }^{*}$ indicates double-blinded, randomized vaccine trial. 
medRxiv preprint doi: https://doi.org/10.1101/2021.05.20.21257461; this version posted June 18, 2021. The copyright holder for this preprint (which was not certified by peer review) is the author/funder, who has granted medRxiv a license to display the preprint in perpetuity.

It is made available under a CC-BY 4.0 International license .

\begin{tabular}{|c|c|c|c|c|}
\hline Vaccine & & & & Vaccine efficacy \\
\hline \multicolumn{4}{|l|}{ AstraZeneca* } & $-1.000[\mathrm{Cl}$ not reported] \\
\hline \multicolumn{4}{|l|}{ Johnson \& Johnson* } & $-1.000[\mathrm{Cl}$ not reported $]$ \\
\hline \multicolumn{4}{|l|}{ Novavax* } & 1.000 [Cl not reported] \\
\hline \multicolumn{4}{|l|}{ Sinovac* } & $\longrightarrow 1.000[0.534,1.000]$ \\
\hline \multicolumn{4}{|l|}{ Pfizer } & $\quad 0.720[0.190,1.000]$ \\
\hline$\Gamma$ & $T$ & $T$ & $T$ & 7 \\
\hline 0.000 & 0.250 & 0.500 & 0.750 & 1.000 \\
\hline
\end{tabular}

Figure 6: Forest plot of vaccine efficacy to prevent death, $\boldsymbol{V} \boldsymbol{E}_{S P}^{D}{ }^{*}$ indicates double-blinded, randomized vaccine trial.

Figure 7 (Table A7) give the estimates of the $V E_{S}$, i.e., VE against infection. The estimates were quite high, with a summary estimate of $84 \%$ (95\% CI: 70 - 91\%).

\begin{tabular}{|c|c|c|c|c|}
\hline Vaccine & & & & Vaccine efficacy \\
\hline Moderna & & & 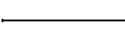 & $0.900[0.680,0.970]$ \\
\hline Pfizer & & & & $0.900[0.680,0.970]$ \\
\hline AstraZeneca* & & & - & $0.773[0.654,0.850]$ \\
\hline \multirow[t]{3}{*}{ VE Estimate } & & & $\longrightarrow$ & $0.839[0.697,0.914]$ \\
\hline & $T$ & $T$ & $T$ & \\
\hline & 0.250 & 0.500 & 0.750 & 1.000 \\
\hline
\end{tabular}

Figure 7: Forest plot of vaccine efficacy to prevent infection, $\boldsymbol{V} \boldsymbol{E}_{S} .{ }^{*}$ indicates double-blinded, randomized vaccine trial. 
medRxiv preprint doi: https://doi.org/10.1101/2021.05.20.21257461; this version posted June 18, 2021. The copyright holder for this preprint (which was not certified by peer review) is the author/funder, who has granted medRxiv a license to display the preprint in perpetuity.

It is made available under a CC-BY 4.0 International license .

(Table A8) give estimates of the $V E_{I}$, i.e., VE against infectiousness or direct transmission to others. The summary measure is $48 \%$ (95\% CI: 45 - 52\%), indicating the vaccination reduces the transmission to others by $48 \%$ when vaccinated people are infected, compared to unvaccinated people who become infected.

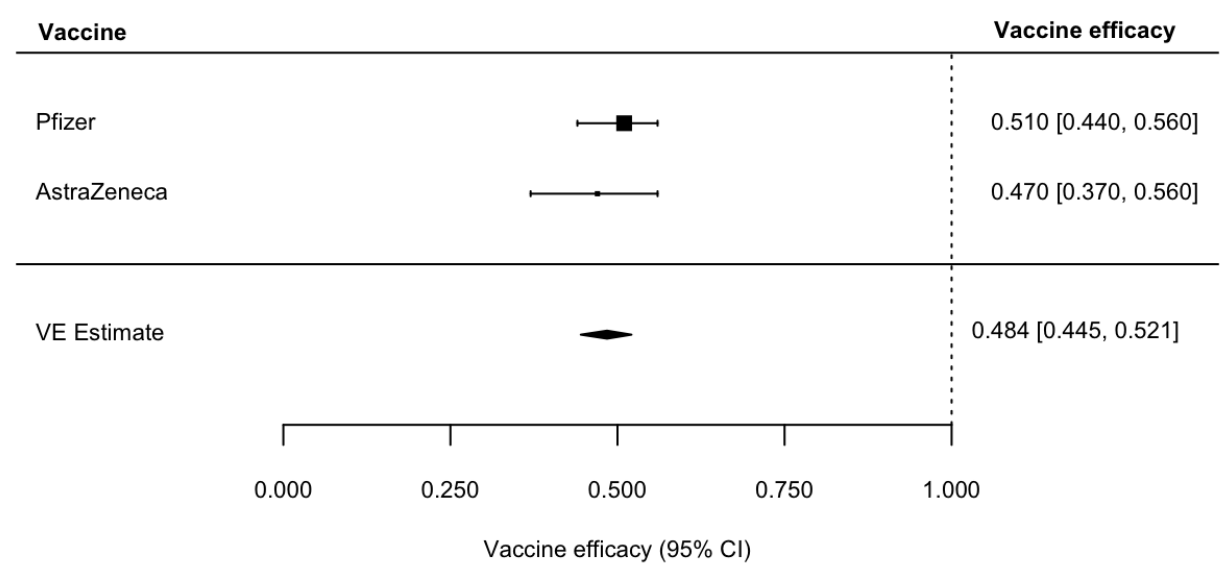

Figure 8: Forest plot of vaccine efficacy to prevent infectiousness to others, $V E_{I}$

Now we consider VE's for the variants of concern (VOC). Estimates are available for the $V E_{S P}$, mostly after the first dose for the one dose vaccine and the second dose for the two dose vaccines. These estimates are given in Figures 9-15 (Tables A9-A15).

For $\alpha$ (B.1.1.7), VE is $48 \%$ (95\% CI: $44-51 \%)$ after dose 1, and VE is $85 \%$ (95\% CI: 25 $97 \%$ ) after dose 2 . The summary estimate for VE after dose 1 is considerably lower than the VE for the wild type virus. In contrast, however, the summary estimate after dose 2 is just somewhat reduced compared to the wild type virus. It is necessary to note that this VOC does not have a mutation that affects immunity, whereas the other VOC's have mutations that affect immune function. 
medRxiv preprint doi: https://doi.org/10.1101/2021.05.20.21257461; this version posted June 18, 2021. The copyright holder for this preprint (which was not certified by peer review) is the author/funder, who has granted medRxiv a license to display the preprint in perpetuity.

It is made available under a CC-BY 4.0 International license .

Figure 9: Forest plot of vaccine efficacy against $\alpha$ (B.1.1.7) after dose 1

\begin{tabular}{|c|c|c|c|c|c|}
\hline Vaccine & & & & & Vaccine efficacy \\
\hline AstraZeneca & \multicolumn{4}{|c|}{$\mapsto$} & $0.514[0.473,0.552]$ \\
\hline Pfizer & \multicolumn{4}{|c|}{$\longmapsto$} & $0.493[0.426,0.550]$ \\
\hline \multirow[t]{3}{*}{ VE Estimate } & & & - & & \multirow[t]{2}{*}{$0.478[0.440,0.513]$} \\
\hline & $\Gamma$ & $T$ & $T$ & $T$ & \\
\hline & 0.000 & 0.250 & 0.500 & 0.750 & 1.000 \\
\hline
\end{tabular}

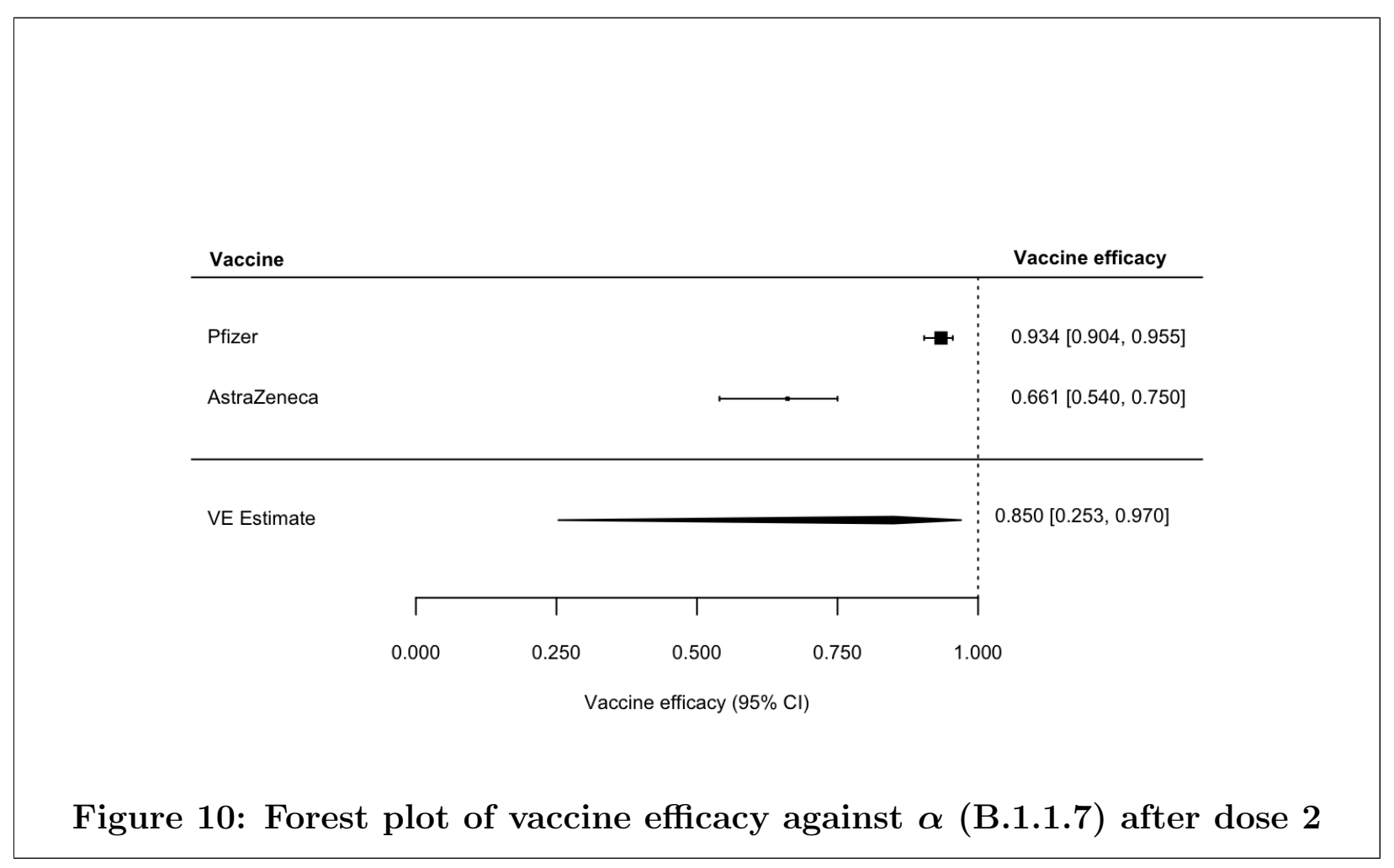


medRxiv preprint doi: https://doi.org/10.1101/2021.05.20.21257461; this version posted June 18, 2021. The copyright holder for this preprint (which was not certified by peer review) is the author/funder, who has granted medRxiv a license to display the preprint in perpetuity.

It is made available under a CC-BY 4.0 International license .

The average VE for the VOC $\gamma(\mathrm{P} 1)$ is $61 \%$ (95\% CI: $43-73 \%)$. For $\beta$ (B.1.351), VE is $35 \%$ (95\% CI: $-11-62 \%$ ) after dose 1, and VE is $57 \%$ (95\% CI: $14-78 \%$ ) after dose 2 . The summary estimates for VE after dose 1 and dose 2 are considerably lower than the VE's for the wild type virus.

For $\delta$ (B.1.617.2), VE is 33\% (95\% CI: 21 - 43\%) after dose 1, and VE is $78 \%$ (95\% CI: $28-93 \%$ ) after dose 2. The summary estimate for VE after dose 1 is considerably lower than the VE for the wild type virus. In contrast, however, the summary estimate after dose 2 is just somewhat reduced compared to the wild type virus.

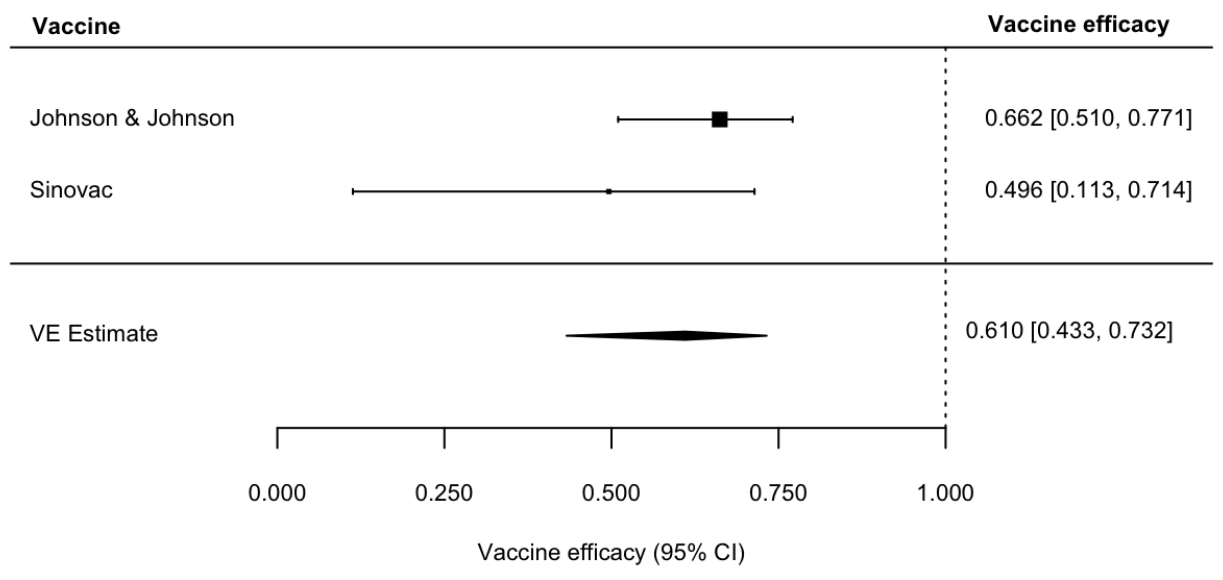

Figure 11: Forest plot of vaccine efficacy against $(\gamma)($ P.1) 
medRxiv preprint doi: https://doi.org/10.1101/2021.05.20.21257461; this version posted June 18, 2021. The copyright holder for this preprint (which was not certified by peer review) is the author/funder, who has granted medRxiv a license to display the preprint in perpetuity.

It is made available under a CC-BY 4.0 International license .

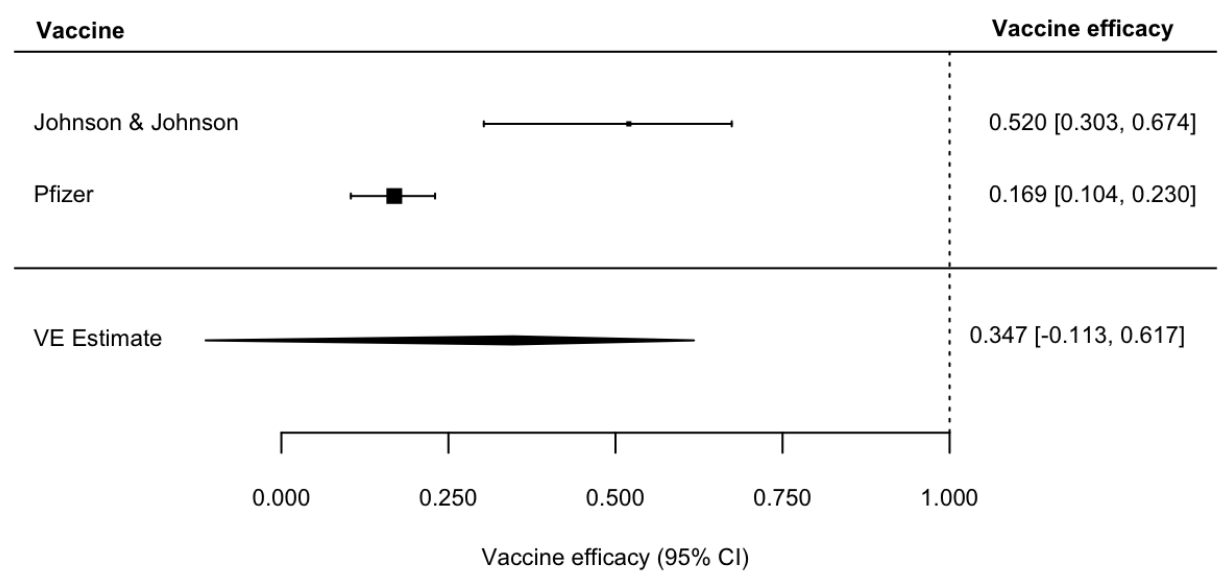

Figure 12: Forest plot of vaccine efficacy against $\beta$ (B.1.351) after dose 1

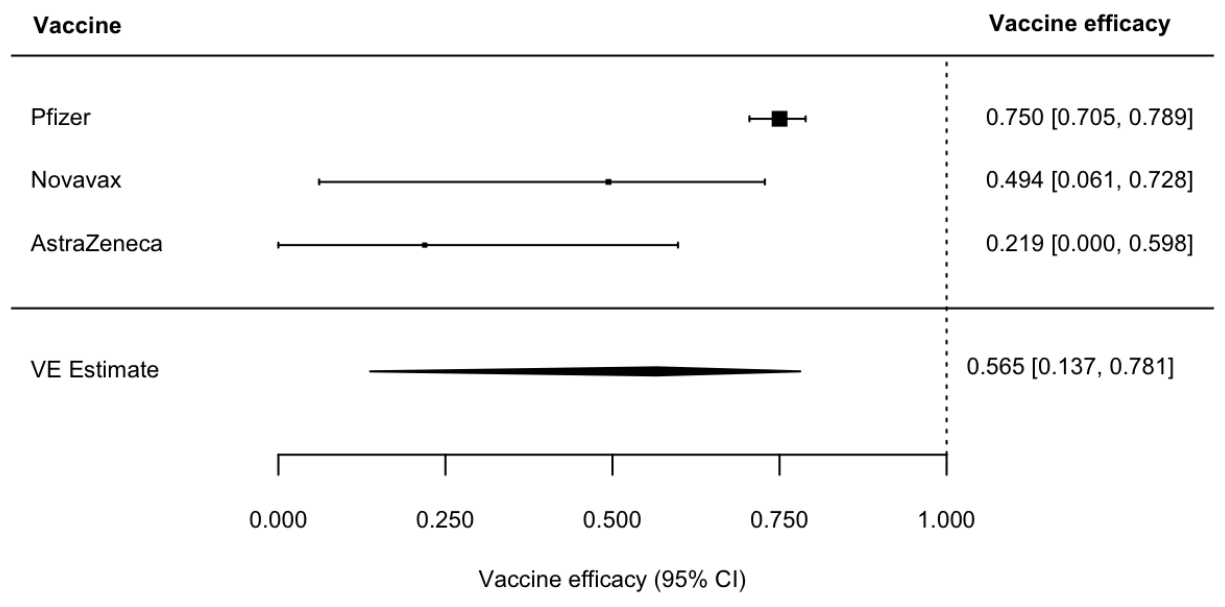

Figure 13: Forest plot of vaccine efficacy against $\beta$ (B.1.351) after dose 2 
medRxiv preprint doi: https://doi.org/10.1101/2021.05.20.21257461; this version posted June 18, 2021. The copyright holder for this preprint (which was not certified by peer review) is the author/funder, who has granted medRxiv a license to display the preprint in perpetuity.

It is made available under a CC-BY 4.0 International license .

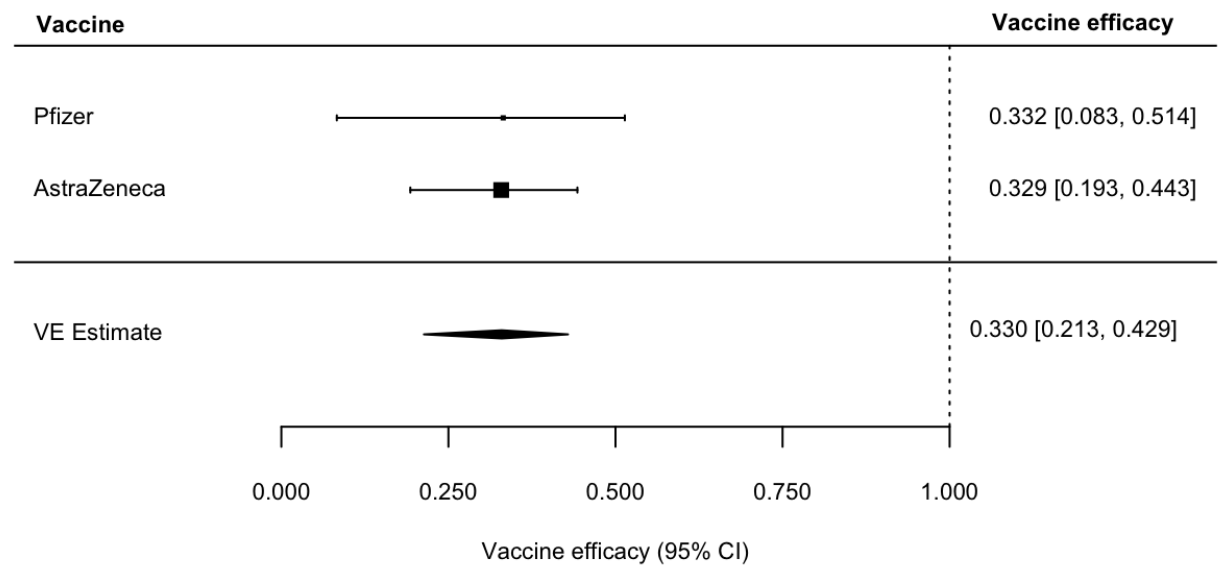

Figure 14: Forest plot of vaccine efficacy against $\delta$ (B.1.617.2) after dose 1

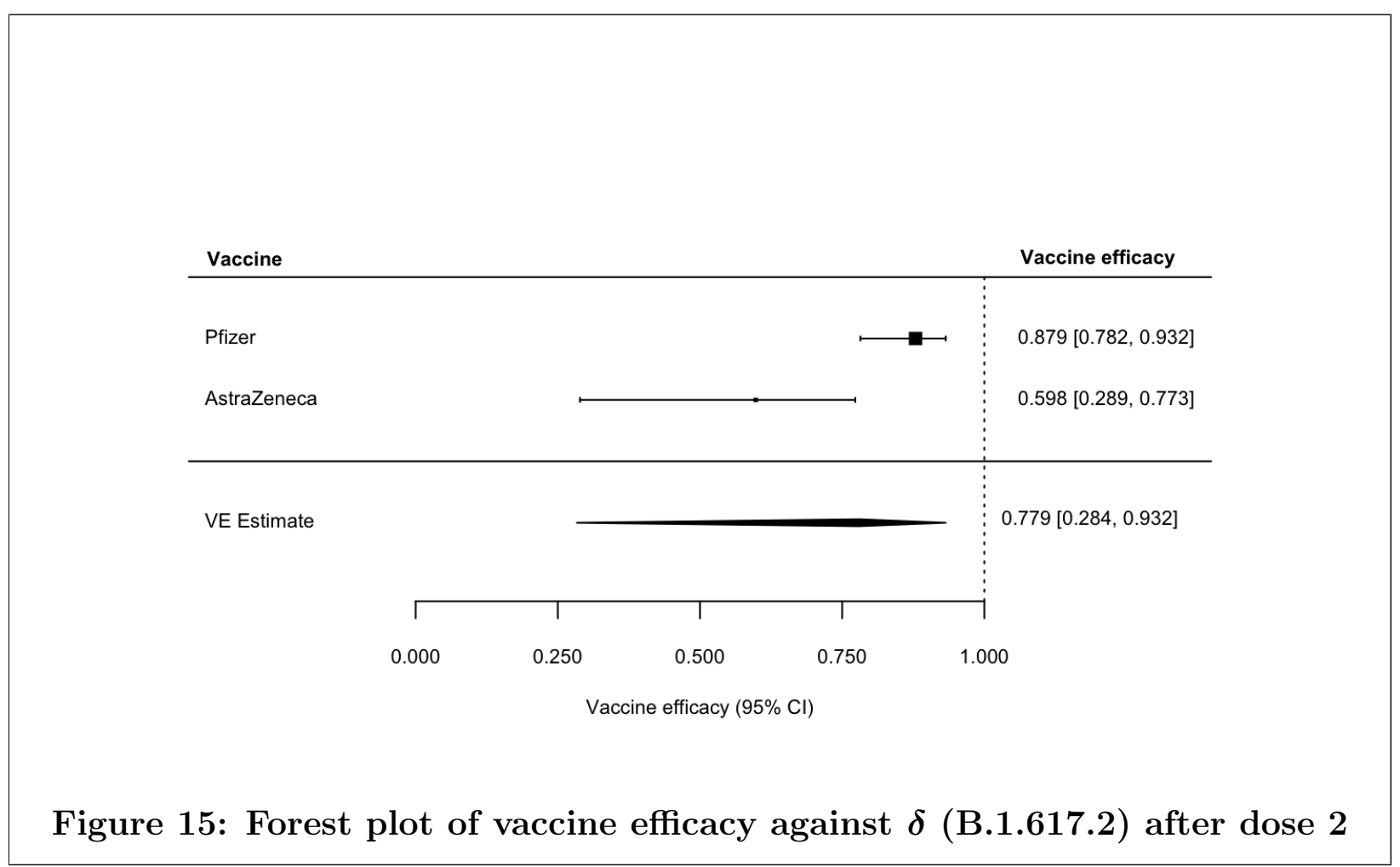




\section{Discussion}

We have presented the relevant VE estimates for the COVID-19 vaccines that are being rolled out on a global scale and for which there is sufficient quality data. We provide estimates of VE against disease with confirmed infection, infection, and transmission to others. The VE estimates against disease are stratified by disease severity, hospitalization and death. We have also provided VE estimates for three of the VOC.

These estimates should be useful for constructing mathematical models for vaccination impact and for making policy decisions involving vaccination. We plan to keep updating this report as more information becomes available.

\section{Methods}

For each vaccine efficacy measure (e.g., severe disease, infection), we first obtained log odds ratios and corresponding sampling variances from each vaccine efficacy estimate and $95 \%$ confidence interval (CI). We then fit random-effects models to these data to estimate average log odds ratios, which we back-transformed to obtain VE summary estimates and 95\% CIs. All analyses were done in $\mathrm{R}$ version 4.0.2 using the package metafor ( $\mathrm{R}$ Project for Statistical Computing) $[2,3]$.

\section{Funding}

This work was partially funded by NIH grants R01AI139761 and R56AI148284. 
medRxiv preprint doi: https://doi.org/10.1101/2021.05.20.21257461; this version posted June 18, 2021. The copyright holder for this preprint (which was not certified by peer review) is the author/funder, who has granted medRxiv a license to display the preprint in perpetuity.

It is made available under a CC-BY 4.0 International license .

\section{Appendix}

Here we give the details about the studies and data that are summarized in the figures.

Note: * indicates that the VE estimate is based on double-blinded, randomized trials.

Table 1: Vaccine efficacy to prevent any disease after dose $2, V E_{S P}$

\begin{tabular}{|c|c|c|}
\hline Company & $\begin{array}{l}\text { Efficacy } \%,(95 \% \mathrm{CI}), \\
\text { time frame of estimate }\end{array}$ & References \\
\hline Moderna & $\begin{array}{l}94.5^{\star},(86.5,97.8), 14 \text { or } \\
\text { more days after dose } 2\end{array}$ & {$[4]$} \\
\hline Pfizer & $\begin{array}{l}94.2^{\star},(88.7,97.2), 14 \text { or } \\
\text { more days after dose } 2\end{array}$ & {$[5]$} \\
\hline Johnson \& Johnson & One dose vaccine & $\mathrm{n} / \mathrm{a}$ \\
\hline AstraZeneca & $\begin{array}{l}81.5^{\star},(67.9,89.4), 14 \text { or } \\
\text { more days after dose } 2\end{array}$ & {$[6]$} \\
\hline Novavax & $\begin{array}{l}89.3^{\star},(75.2,95.4), 7 \text { or } \\
\text { more days after dose } 2\end{array}$ & {$[7]$} \\
\hline Sputnik V & Not reported & $\mathrm{n} / \mathrm{a}$ \\
\hline Sinovac & $\begin{array}{l}50.7^{\star},(35.7,62.2), \text { time } \\
\text { frame not reported }\end{array}$ & {$[8]$} \\
\hline Sinopharm & $\begin{array}{l}78.1^{\star},(64.9,86.3), \text { median } \\
\text { follow-up time } 112 \text { days }\end{array}$ & {$[9]$} \\
\hline
\end{tabular}


medRxiv preprint doi: https://doi.org/10.1101/2021.05.20.21257461; this version posted June 18, 2021. The copyright holder for this preprint (which was not certified by peer review) is the author/funder, who has granted medRxiv a license to display the preprint in perpetuity.

It is made available under a CC-BY 4.0 International license .

Table 2: Vaccine efficacy to prevent any disease after dose $1, V E_{S P}$

\begin{tabular}{|c|c|c|}
\hline Company & $\begin{array}{l}\text { Efficacy } \%,(95 \% \mathrm{CI}) \text {, } \\
\text { time frame of estimate }\end{array}$ & References \\
\hline Moderna & $\begin{array}{l}92.1^{\star},(68.8,99.1), \text { more } \\
\text { than } 14 \text { days after dose } 1\end{array}$ & {$[4]$} \\
\hline Pfizer & $\begin{array}{l}82.0^{\star},(75.6,86.9), \text { after } \\
\text { dose } 1 \\
57.0,(50.0,60.0), 14-20 \\
\text { day period after dose } 1\end{array}$ & $\begin{array}{l}{[5]} \\
{[10]}\end{array}$ \\
\hline Johnson \& Johnson & $\begin{array}{l}66.9^{\star},(59.1,73.4), 14 \text { or } \\
\text { more days after vaccination } \\
66.5^{\star},(55.5,75.1), 28 \text { or } \\
\text { more days after vaccination }\end{array}$ & $\begin{array}{l}{[11,12]} \\
{[11,12]}\end{array}$ \\
\hline AstraZeneca & $\begin{array}{l}76.0^{\star},(59.0,86.0), 22-90 \\
\text { day period after dose } 1\end{array}$ & {$[7]$} \\
\hline Novavax & $\begin{array}{l}83.4^{\star},(73.6,89.5), 14 \text { or } \\
\text { more days after dose } 1\end{array}$ & {$[13]$} \\
\hline Sputnik V & $\begin{array}{l}91.6^{\star},(85.6,95.2), 21 \text { days } \\
\text { after dose } 1\end{array}$ & {$[14]$} \\
\hline Sinovac & Not reported & $\mathrm{n} / \mathrm{a}$ \\
\hline Sinopharm & Not reported & $\mathrm{n} / \mathrm{a}$ \\
\hline
\end{tabular}


medRxiv preprint doi: https://doi.org/10.1101/2021.05.20.21257461; this version posted June 18, 2021. The copyright holder for this preprint (which was not certified by peer review) is the author/funder, who has granted medRxiv a license to display the preprint in perpetuity.

It is made available under a CC-BY 4.0 International license .

Table 3: Vaccine efficacy to prevent severe disease after dose $2, V E_{S P}^{S}$

\begin{tabular}{|c|c|c|}
\hline Company & $\begin{array}{l}\text { Efficacy\%, }(95 \% \mathrm{CI}), \\
\text { time frame of estimate }\end{array}$ & References \\
\hline Moderna & $\begin{array}{l}100.0^{\star},(\text { CI not reported }) \\
14 \text { or more days after dose } \\
2\end{array}$ & {$[4]$} \\
\hline Pfizer & $\begin{array}{l}92.0,(75.0,100.0), 7 \text { or } \\
\text { more days after dose } 2\end{array}$ & {$[10]$} \\
\hline Johnson \& Johnson & One dose vaccine & $\mathrm{n} / \mathrm{a}$ \\
\hline AstraZeneca & $\begin{array}{l}100.0^{\star},(\mathrm{CI} \text { not reported }), \\
\text { time frame not reported }\end{array}$ & {$[7]$} \\
\hline Novavax & $\begin{array}{l}100.0^{\star},(\text { CI not reported }), \\
\text { time frame not reported }\end{array}$ & {$[7]$} \\
\hline Sputnik V & Not reported & $\mathrm{n} / \mathrm{a}$ \\
\hline Sinovac & $\begin{array}{l}100.0^{\star},(53.4,100.0)^{a}, \text { time } \\
\text { frame not reported }\end{array}$ & [8] \\
\hline Sinopharm & Not reported & $\mathrm{n} / \mathrm{a}$ \\
\hline
\end{tabular}

${ }^{a}$ Combined estimate of VE against hospitalization, severe disease, and death 
medRxiv preprint doi: https://doi.org/10.1101/2021.05.20.21257461; this version posted June 18, 2021. The copyright holder for this preprint (which was not certified by peer review) is the author/funder, who has granted medRxiv a license to display the preprint in perpetuity.

It is made available under a CC-BY 4.0 International license .

Table 4: Vaccine efficacy to prevent severe disease after dose $1, V E_{S P}^{S}$

\begin{tabular}{|c|c|c|}
\hline Company & $\begin{array}{l}\text { Efficacy } \%,(95 \% \mathrm{CI}) \text {, } \\
\text { time frame of estimate }\end{array}$ & References \\
\hline Moderna & $\begin{array}{l}42.6^{\star},(-300.8,94.8), 14 \text { or } \\
\text { more days after dose } 1\end{array}$ & {$[4]$} \\
\hline Pfizer & $\begin{array}{l}88.9^{\star},(20.1,99.7), \text { after } \\
\text { dose } 1 \\
62.0,(39.0,80.0), 14-20 \\
\text { day period after dose } 1\end{array}$ & $\begin{array}{l}{[5]} \\
{[10]}\end{array}$ \\
\hline Johnson \& Johnson & $\begin{array}{l}76.7^{\star},(54.6,89.9), 14 \text { or } \\
\text { more days after vaccination } \\
85.4^{\star},(54.2,96.9), 28 \text { or } \\
\text { more days after vaccination }\end{array}$ & $\begin{array}{l}{[11,12]} \\
{[11,12]}\end{array}$ \\
\hline AstraZeneca & $\begin{array}{l}100.0^{\star},(\text { CI not reported }) \\
\text { more than } 22 \text { days after } \\
\text { dose } 1\end{array}$ & {$[15]$} \\
\hline Novavax & Not reported & $\mathrm{n} / \mathrm{a}$ \\
\hline Sputnik V & $\begin{array}{l}100.0^{\star},(94.4,100.0), 21 \text { or } \\
\text { more days after dose } 1\end{array}$ & {$[16]$} \\
\hline Sinovac & Not reported & $\mathrm{n} / \mathrm{a}$ \\
\hline Sinopharm & Not reported & $\mathrm{n} / \mathrm{a}$ \\
\hline
\end{tabular}


medRxiv preprint doi: https://doi.org/10.1101/2021.05.20.21257461; this version posted June 18, 2021. The copyright holder for this preprint (which was not certified by peer review) is the author/funder, who has granted medRxiv a license to display the preprint in perpetuity.

It is made available under a CC-BY 4.0 International license.

Table 5: Vaccine efficacy to prevent hospitalization, $V E_{S P}^{H}$

\begin{tabular}{|c|c|c|}
\hline Company & $\begin{array}{l}\text { Efficacy\%, }(95 \% \mathrm{CI}), \\
\text { time frame of estimate }\end{array}$ & References \\
\hline Moderna & $\begin{array}{l}89.0,(13.0,99.0), \text { time } \\
\text { frame not reported }\end{array}$ & {$[17]$} \\
\hline \multirow{3}{*}{ Pfizer } & $\begin{array}{l}87.0,(55.0,100.0), 7 \text { or } \\
\text { more days after dose } 2\end{array}$ & {$[10]$} \\
\hline & $\begin{array}{l}74.0,(56.0,86.0), 14-20 \\
\text { days after dose } 1\end{array}$ & {$[10]$} \\
\hline & $\begin{array}{l}91.0,(85.0,94.0), 28-34 \\
\text { days after a single dose }\end{array}$ & {$[18]$} \\
\hline \multirow[t]{2}{*}{ Johnson \& Johnson } & $\begin{array}{l}93.1^{\star},(72.7,99.2), 14 \text { or } \\
\text { more days after vaccination }\end{array}$ & {$[11,12]$} \\
\hline & $\begin{array}{l}100.0^{\star},(74.3,100.0), 28 \text { or } \\
\text { more days after vaccination }\end{array}$ & {$[11,12]$} \\
\hline \multirow[t]{2}{*}{ AstraZeneca } & $\begin{array}{l}100.0^{\star},(\mathrm{CI} \text { not reported }), \\
\text { more than } 22 \text { days after } \\
\text { dose } 1\end{array}$ & {$[15]$} \\
\hline & $\begin{array}{l}88.0,(75.0,94.0), 28-34 \\
\text { days after a single dose }\end{array}$ & {$[18]$} \\
\hline Novavax & $\begin{array}{l}100.0^{\star},(\mathrm{CI} \text { not reported }), \\
\text { time frame not reported }\end{array}$ & {$[13]$} \\
\hline Sputnik V & Not reported & $\mathrm{n} / \mathrm{a}$ \\
\hline Sinovac & $\begin{array}{l}83.7^{\star},(58.0,93.7), \text { time } \\
\text { frame not reported }\end{array}$ & {$[8]$} \\
\hline Sinopharm & $\begin{array}{l}78.7^{\star},(26.0,93.9), \text { median } \\
\text { follow-up time } 112 \text { days }\end{array}$ & {$[9]$} \\
\hline
\end{tabular}


medRxiv preprint doi: https://doi.org/10.1101/2021.05.20.21257461; this version posted June 18, 2021. The copyright holder for this preprint (which was not certified by peer review) is the author/funder, who has granted medRxiv a license to display the preprint in perpetuity.

It is made available under a CC-BY 4.0 International license .

Table 6: Vaccine efficacy to prevent death, $V E_{S P}^{D}$

\begin{tabular}{|c|c|c|}
\hline Company & $\begin{array}{l}\text { Efficacy } \%,(95 \% \mathrm{CI}), \\
\text { time frame of estimate }\end{array}$ & References \\
\hline Moderna & Not reported & $\mathrm{n} / \mathrm{a}$ \\
\hline Pfizer & $\begin{array}{l}72.0,(19.0,100.0), 14-20 \\
\text { days after dose } 1\end{array}$ & {$[10]$} \\
\hline Johnson \& Johnson & $\begin{array}{l}100.0^{\star},(\mathrm{CI} \text { not reported), } \\
\text { time frame not reported }\end{array}$ & {$[11]$} \\
\hline AstraZeneca & $\begin{array}{l}100.0^{\star},(\mathrm{CI} \text { not reported }), \\
\text { time frame not reported }\end{array}$ & {$[6]$} \\
\hline Novavax & $\begin{array}{l}100.0^{\star},(\mathrm{CI} \text { not reported }), \\
\text { time frame not reported }\end{array}$ & {$[13]$} \\
\hline Sputnik V & Not reported & $\mathrm{n} / \mathrm{a}$ \\
\hline Sinovac & $\begin{array}{l}100.0^{\star},(53.4,100.0)^{a}, \text { time } \\
\text { frame not reported }\end{array}$ & {$[8]$} \\
\hline Sinopharm & Not reported & $\mathrm{n} / \mathrm{a}$ \\
\hline
\end{tabular}

${ }^{a}$ Combined estimate of VE against hospitalization, severe disease, and death 
medRxiv preprint doi: https://doi.org/10.1101/2021.05.20.21257461; this version posted June 18, 2021. The copyright holder for this preprint (which was not certified by peer review) is the author/funder, who has granted medRxiv a license to display the preprint in perpetuity.

It is made available under a CC-BY 4.0 International license .

Table 7: Vaccine efficacy to prevent infection, $\boldsymbol{V} \boldsymbol{E}_{S}$

\begin{tabular}{|c|c|c|}
\hline Company & $\begin{array}{l}\text { Efficacy } \% \text {, }(95 \% \mathrm{CI}) \text {, time } \\
\text { frame of estimate }\end{array}$ & References \\
\hline Moderna & $\begin{array}{l}90.0,(68.0,97.0)^{c}, 14 \text { or more days } \\
\text { after dose } 2 \\
80.0,(59.0,90.0)^{c}, 14 \text { or more days } \\
\text { after dose } 1 \text { but before dose } 2\end{array}$ & $\begin{array}{l}{[19]} \\
{[19]}\end{array}$ \\
\hline Pfizer & $\begin{array}{l}70.0,(55.0,85.0)^{d}, 21 \text { days after } \\
\text { dose } 1 \\
85.0,(74.0,96.0)^{d}, 7 \text { days after dose } \\
2 \\
90.0,(68.0,97.0)^{c}, 14 \text { or more days } \\
\text { after dose } 2 \\
80.0,(59.0,90.0)^{c}, 14 \text { or more days } \\
\text { after dose } 1 \text { but before dose } 2 \\
51.4,(16.3,71.8)^{d}, 13-24 \text { day pe- } \\
\text { riod after dose } 1 \text { compared to the } \\
\text { preceding } 1-12 \text { days }\end{array}$ & $\begin{array}{l}{[20]} \\
{[20]} \\
{[19]} \\
{[19]} \\
{[21]}\end{array}$ \\
\hline Johnson \& Johnson & Not reported & $\mathrm{n} / \mathrm{a}$ \\
\hline AstraZeneca & $\begin{array}{l}77.3^{\star},(65.4,85.0)^{e}, \text { more than } 14 \\
\text { days after dose } 2 \\
51.9,(42.0,60.1)^{d}, \text { time frame not } \\
\text { reported }\end{array}$ & $\begin{array}{l}{[6]} \\
{[20]}\end{array}$ \\
\hline Novavax & Not reported & $\mathrm{n} / \mathrm{a}$ \\
\hline Sputnik V & Not reported & $\mathrm{n} / \mathrm{a}$ \\
\hline Sinovac & Not reported & $\mathrm{n} / \mathrm{a}$ \\
\hline Sinopharm & Not reported & $\mathrm{n} / \mathrm{a}$ \\
\hline
\end{tabular}


medRxiv preprint doi: https://doi.org/10.1101/2021.05.20.21257461; this version posted June 18, 2021. The copyright holder for this preprint (which was not certified by peer review) is the author/funder, who has granted medRxiv a license to display the preprint in perpetuity.

It is made available under a CC-BY 4.0 International license .

${ }^{c}$ mRNA vaccine effectiveness for prevention of infection.

${ }^{d}$ VE against all (symptomatic and asymptomatic) infection.

${ }^{e} \mathrm{VE}$ against all (symptomatic and asymptomatic) infection caused by non-B.1.1.7 variants. Asymptomatic infections were detected by weekly swabbing. 
medRxiv preprint doi: https://doi.org/10.1101/2021.05.20.21257461; this version posted June 18, 2021. The copyright holder for this preprint (which was not certified by peer review) is the author/funder, who has granted medRxiv a license to display the preprint in perpetuity.

It is made available under a CC-BY 4.0 International license .

Table 8: Vaccine efficacy to prevent infectiousness to others, $V \boldsymbol{E}_{I}$

\begin{tabular}{||l|l|l||}
\hline \hline Company & $\begin{array}{l}\text { Efficacy\%, (95\% CI), } \\
\text { time frame of estimate }\end{array}$ & References \\
\hline \hline Moderna & Not reported & $\mathrm{n} / \mathrm{a}$ \\
\hline \hline Pfizer & $\begin{array}{l}51.0,(44.0,56.0), \text { after } \\
\text { dose } 2\end{array}$ & {$[22]$} \\
\hline \hline Johnson \& Johnson & Not reported & $\mathrm{n} / \mathrm{a}$ \\
\hline \hline AstraZeneca & $\begin{array}{l}47.0,(37.0,56.0), \text { after } \\
\text { dose } 2\end{array}$ & {$[22]$} \\
\hline \hline Novavax & Not reported & $\mathrm{n} / \mathrm{a}$ \\
\hline \hline Sputnik V & Not reported & $\mathrm{n} / \mathrm{a}$ \\
\hline \hline Sinovac & Not reported & $\mathrm{n} / \mathrm{a}$ \\
\hline \hline Sinopharm & Not reported & \\
\hline \hline
\end{tabular}


medRxiv preprint doi: https://doi.org/10.1101/2021.05.20.21257461; this version posted June 18, 2021. The copyright holder for this preprint (which was not certified by peer review) is the author/funder, who has granted medRxiv a license to display the preprint in perpetuity.

It is made available under a CC-BY 4.0 International license .

Table 9: Vaccine efficacy against $\alpha$ (B.1.1.7) after dose 1

\begin{tabular}{|c|c|c|}
\hline Company & $\begin{array}{l}\text { Efficacy } \%,(95 \% \mathrm{CI}) \text {, } \\
\text { time frame of estimate }\end{array}$ & References \\
\hline Moderna & Not reported ${ }^{m}$ & {$[23]$} \\
\hline \multirow{3}{*}{ Pfizer } & $\begin{array}{l}29.5,(22.9,35.5)^{n} \text {, after } \\
\text { dose } 1\end{array}$ & {$[23,24]$} \\
\hline & $\begin{array}{l}54.1,(26.1,71.9)^{u}, \text { after } \\
\text { dose } 1\end{array}$ & {$[24]$} \\
\hline & $\begin{array}{l}49.2,(42.6,55.0)^{q}, \text { after } \\
\text { dose } 1\end{array}$ & {$[25]$} \\
\hline Johnson \& Johnson & Not reported ${ }^{p}$ & {$[23]$} \\
\hline AstraZeneca & $\begin{array}{l}51.4,(47.3,55.2)^{q} \text {, after } \\
\text { dose } 1\end{array}$ & {$[25]$} \\
\hline Novavax & $\begin{array}{l}85.6^{\star q},(\text { CI not reported }), \\
\text { time frame not reported }\end{array}$ & {$[23,26]$} \\
\hline Sputnik V & Not reported & $\mathrm{n} / \mathrm{a}$ \\
\hline Sinovac & Not reported & $\mathrm{n} / \mathrm{a}$ \\
\hline Sinopharm & Not reported & $\mathrm{n} / \mathrm{a}$ \\
\hline
\end{tabular}


medRxiv preprint doi: https://doi.org/10.1101/2021.05.20.21257461; this version posted June 18, 2021. The copyright holder for this preprint (which was not certified by peer review) is the author/funder, who has granted medRxiv a license to display the preprint in perpetuity.

It is made available under a CC-BY 4.0 International license .

$m$ Although a VE estimate is unknown, numerous studies have reported that the Moderna vaccine offers protection against the $\alpha$ (B.1.1.7) variant [26-28].

${ }^{n}$ VE against PCR-confirmed infection with the $\alpha$ (B.1.1.7) variant.

${ }^{u}$ VE against severe, critical, or fatal disease caused by the $\alpha$ (B.1.1.7) variant.

$\boldsymbol{p}$ There is no VE estimate reported, but it is important to note that the Johnson \& Johnson vaccine was tested in the US after the $\alpha$ (B.1.1.7) variant was circulating.

${ }^{q}$ VE against symptomatic COVID-19

${ }^{r}$ VE against all (symptomatic and asymptomatic) infection caused by the $\alpha$ (B.1.1.7) variant. Asymptomatic infections were detected by weekly swabbing. 
medRxiv preprint doi: https://doi.org/10.1101/2021.05.20.21257461; this version posted June 18, 2021. The copyright holder for this preprint (which was not certified by peer review) is the author/funder, who has granted medRxiv a license to display the preprint in perpetuity.

It is made available under a CC-BY 4.0 International license .

Table 10: Vaccine efficacy against $\alpha($ B.1.1.7) after dose 2

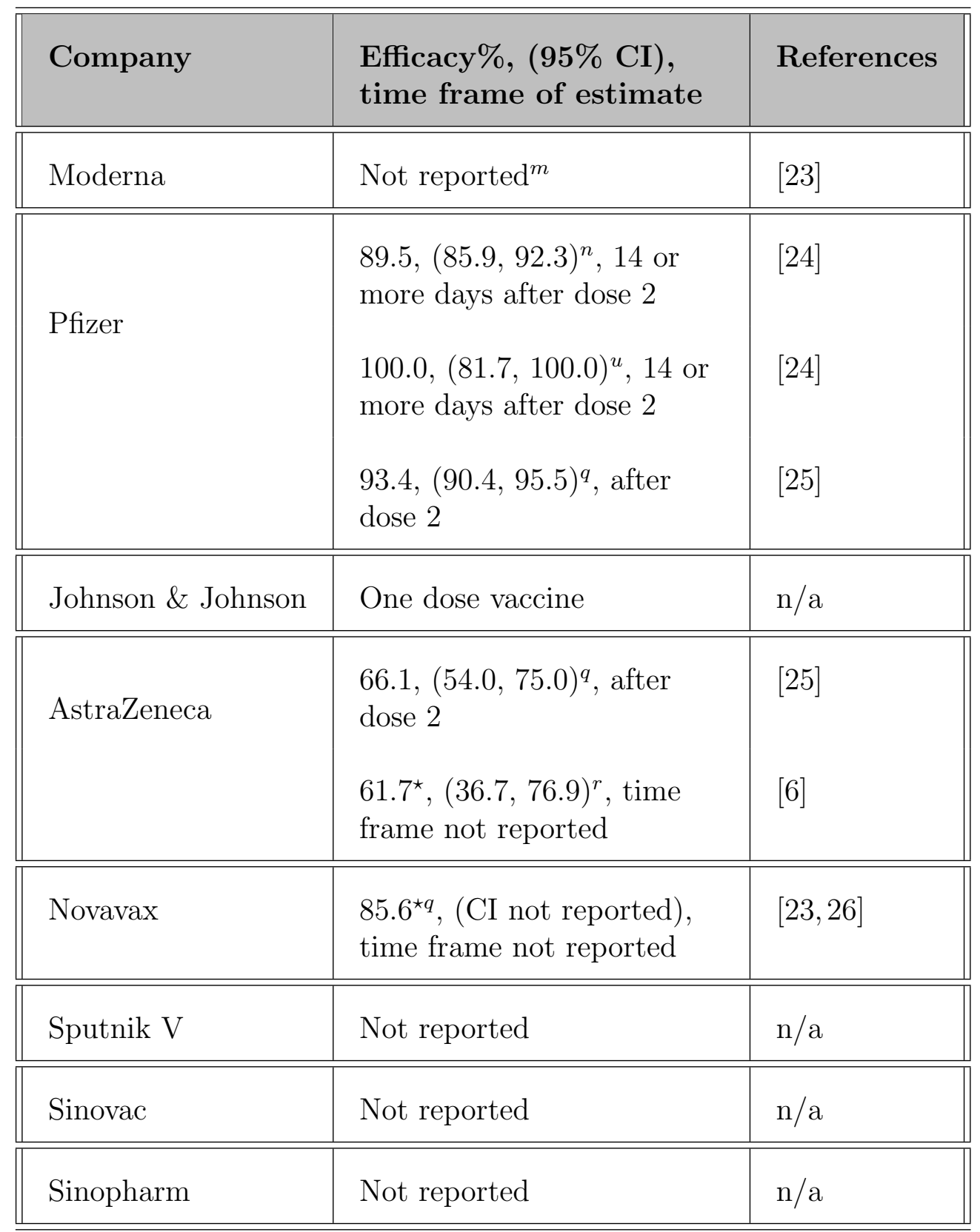


medRxiv preprint doi: https://doi.org/10.1101/2021.05.20.21257461; this version posted June 18, 2021. The copyright holder for this preprint (which was not certified by peer review) is the author/funder, who has granted medRxiv a license to display the preprint in perpetuity.

It is made available under a CC-BY 4.0 International license.

$m$ Although a VE estimate is unknown, numerous studies have reported that the Moderna vaccine offers protection against the B.1.1.7 variant [26-28].

${ }^{n}$ VE against PCR-confirmed infection with the $\alpha$ (B.1.1.7) variant.

${ }^{u}$ VE against severe, critical, or fatal disease caused by the $\alpha$ (B.1.1.7) variant.

${ }^{\boldsymbol{q}}$ VE against symptomatic COVID-19

${ }^{r}$ VE against all (symptomatic and asymptomatic) infection caused by the $\alpha$ (B.1.1.7) variant. Asymptomatic infections were detected by weekly swabbing. 
medRxiv preprint doi: https://doi.org/10.1101/2021.05.20.21257461; this version posted June 18, 2021. The copyright holder for this preprint (which was not certified by peer review) is the author/funder, who has granted medRxiv a license to display the preprint in perpetuity.

It is made available under a CC-BY 4.0 International license .

Table 11: Vaccine efficacy against $\gamma($ P.1)

\begin{tabular}{||l|l|l||}
\hline \hline Company & $\begin{array}{l}\text { Efficacy\%, }(95 \% \text { CI }), \\
\text { time frame of estimate }\end{array}$ & References \\
\hline \hline Moderna & Not reported & $\mathrm{n} / \mathrm{a}$ \\
\hline \hline Pfizer & Not reported & $\mathrm{n} / \mathrm{a}$ \\
\hline \hline Johnson \& Johnson & $\begin{array}{l}66.2^{\star},(51.0,77.1)^{s}, 14 \text { or } \\
\text { more days after vaccination } \\
68.1^{\star},(48.8,80.7)^{s}, 28 \text { or } \\
\text { more days after vaccination }\end{array}$ & {$[12]$} \\
\hline \hline AstraZeneca & Not reported & $\mathrm{n} / \mathrm{a}$ \\
\hline \hline Novavax & Not reported & $\mathrm{n} / \mathrm{a}$ \\
\hline \hline Sputnik V & Not reported & $\mathrm{n} / \mathrm{a}$ \\
\hline \hline Sinovac & $\begin{array}{l}49.6,(11.3,71.4)^{t}, 14 \text { or } \\
\text { more days after dose } 1\end{array}$ & {$[29]$} \\
\hline \hline Sinopharm & Not reported & $\mathrm{n} / \mathrm{a}$ \\
\hline \hline
\end{tabular}

$s$ VE against moderate to severe Covid-19 caused by the variant from the P.2 lineage carrying the E484K mutation.

${ }^{t}$ VE against symptomatic infection 
medRxiv preprint doi: https://doi.org/10.1101/2021.05.20.21257461; this version posted June 18, 2021. The copyright holder for this preprint (which was not certified by peer review) is the author/funder, who has granted medRxiv a license to display the preprint in perpetuity.

It is made available under a CC-BY 4.0 International license.

Table 12: Vaccine efficacy against $\beta$ (B.1.351) after dose 1

\begin{tabular}{|c|c|c|}
\hline Company & $\begin{array}{l}\text { Efficacy\%, }(95 \% \mathrm{CI}) \text {, } \\
\text { time frame of estimate }\end{array}$ & References \\
\hline Moderna & Not reported & $\mathrm{n} / \mathrm{a}$ \\
\hline Pfizer & $\begin{array}{l}16.9,(10.4,23.0)^{n}, \text { after } \\
\text { dose } 1 \\
0.0,(0.0,19.0)^{u}, \text { after dose } \\
1\end{array}$ & $\begin{array}{l}{[23,24]} \\
{[24]}\end{array}$ \\
\hline Johnson \& Johnson & $\begin{array}{l}52.0^{\star},(30.3,67.4)^{w}, 14 \text { or } \\
\text { more days after vaccination } \\
64.0^{\star},(41.2,78.7)^{w}, 28 \text { or } \\
\text { more days after vaccination }\end{array}$ & $\begin{array}{l}{[12]} \\
{[12]}\end{array}$ \\
\hline AstraZeneca & $\begin{array}{l}21.9^{\star q},(-49.9,59.8), \text { time } \\
\text { frame not reported }\end{array}$ & {$[23,30]$} \\
\hline Novavax & Not reported & $\mathrm{n} / \mathrm{a}$ \\
\hline Sputnik V & Not reported & $\mathrm{n} / \mathrm{a}$ \\
\hline Sinovac & Not reported & $\mathrm{n} / \mathrm{a}$ \\
\hline Sinopharm & Not reported & $\mathrm{n} / \mathrm{a}$ \\
\hline
\end{tabular}

${ }^{n}$ VE against PCR-confirmed infection with the $\beta$ (B.1.351) variant.

${ }^{u}$ VE against severe, critical, or fatal disease caused by the $\beta$ (B.1.351) variant.

$\boldsymbol{w}$ VE against moderate to severe COVID-19

$\boldsymbol{q}$ VE against symptomatic COVID-19 
medRxiv preprint doi: https://doi.org/10.1101/2021.05.20.21257461; this version posted June 18, 2021. The copyright holder for this preprint (which was not certified by peer review) is the author/funder, who has granted medRxiv a license to display the preprint in perpetuity.

It is made available under a CC-BY 4.0 International license .

Table 13: Vaccine efficacy against $\beta$ (B.1.351) after dose 2

\begin{tabular}{||l|l|l||}
\hline \hline Company & $\begin{array}{l}\text { Efficacy\%, (95\% CI), } \\
\text { time frame of estimate }\end{array}$ & References \\
\hline \hline Moderna & Not reported & $\mathrm{n} / \mathrm{a}$ \\
\hline \hline Pfizer & $\begin{array}{l}75.0,(70.5,78.9)^{n}, 14 \text { or } \\
\text { more days after dose } 2\end{array}$ & {$[24]$} \\
\hline \hline Johnson \& Johnson & One dose vaccine & $\mathrm{n} / \mathrm{a}$ \\
\hline \hline AstraZeneca & $\begin{array}{l}21.9^{\star},(-49.9,59.8)^{q}, \text { time } \\
\text { frame not reported }\end{array}$ & {$[23,30]$} \\
\hline \hline Novavax & $\begin{array}{l}49.4^{\star},(6.1,72.8)^{q}, 7 \text { days } \\
\text { after dose } 2\end{array}$ & {$[23,31]$} \\
\hline \hline Sputnik V & Not reported & $\mathrm{n} / \mathrm{a}$ \\
\hline \hline Sinovac & Not reported & $\mathrm{n} / \mathrm{a}$ \\
\hline \hline Sinopharm & Not reported & \\
\hline \hline
\end{tabular}

${ }^{n}$ VE against PCR-confirmed infection with the $\beta$ (B.1.351) variant.

${ }^{q}$ VE against symptomatic COVID-19 
medRxiv preprint doi: https://doi.org/10.1101/2021.05.20.21257461; this version posted June 18, 2021. The copyright holder for this preprint (which was not certified by peer review) is the author/funder, who has granted medRxiv a license to display the preprint in perpetuity.

It is made available under a CC-BY 4.0 International license .

Table 14: Vaccine efficacy against $\delta($ B.1.617.2) after dose 1

\begin{tabular}{||l|l|l||}
\hline \hline Company & $\begin{array}{l}\text { Efficacy\%, (95\% CI), } \\
\text { time frame of estimate }\end{array}$ & References \\
\hline \hline Moderna & Not reported & $\mathrm{n} / \mathrm{a}$ \\
\hline \hline Pfizer & $33.2,(8.3,51.4)^{q}$, after dose & {$[25]$} \\
\hline \hline Johnson \& Johnson & Not reported & $\mathrm{n} / \mathrm{a}$ \\
\hline \hline AstraZeneca & $32.9,(19.3,44.3)^{q}$, after & {$[25]$} \\
\hline \hline Nose 1 & $\mathrm{n} / \mathrm{a}$ \\
\hline \hline Novavax & Not reported & $\mathrm{n} / \mathrm{a}$ \\
\hline Sputnik V & Not reported & $\mathrm{n} / \mathrm{a}$ \\
\hline \hline Sinovac & Not reported & $\mathrm{n} / \mathrm{a}$ \\
\hline \hline Sinopharm & Not reported & \\
\hline \hline
\end{tabular}

$\boldsymbol{q}$ VE against symptomatic COVID-19 
medRxiv preprint doi: https://doi.org/10.1101/2021.05.20.21257461; this version posted June 18, 2021. The copyright holder for this preprint (which was not certified by peer review) is the author/funder, who has granted medRxiv a license to display the preprint in perpetuity.

It is made available under a CC-BY 4.0 International license .

Table 15: Vaccine efficacy against $\delta$ (B.1.617.2) after dose 2

\begin{tabular}{||l|l|l||}
\hline \hline Company & $\begin{array}{l}\text { Efficacy\%, (95\% CI), } \\
\text { time frame of estimate }\end{array}$ & References \\
\hline \hline Moderna & Not reported & $\mathrm{n} / \mathrm{a}$ \\
\hline \hline Pfizer & $\begin{array}{l}87.9,(78.2,93.2)^{q}, \text { after } \\
\text { dose } 2\end{array}$ & {$[25]$} \\
\hline \hline Johnson \& Johnson & Not reported & $\mathrm{n} / \mathrm{a}$ \\
\hline \hline AstraZeneca & $\begin{array}{l}59.8,(28.9,77.3)^{q}, \text { after } \\
\text { dose } 2\end{array}$ & {$[25]$} \\
\hline \hline Novavax & Not reported & $\mathrm{n} / \mathrm{a}$ \\
\hline \hline Sputnik V & Not reported & $\mathrm{n} / \mathrm{a}$ \\
\hline \hline Sinovac & Not reported & $\mathrm{n} / \mathrm{a}$ \\
\hline \hline Sinopharm & Not reported & \\
\hline \hline
\end{tabular}

${ }^{q}$ VE against symptomatic COVID-19 
medRxiv preprint doi: https://doi.org/10.1101/2021.05.20.21257461; this version posted June 18, 2021. The copyright holder for this preprint (which was not certified by peer review) is the author/funder, who has granted medRxiv a license to display the preprint in perpetuity.

It is made available under a CC-BY 4.0 International license .

Table 16: Viral neutralization of the variants of concern as compared with preexisting variants

\begin{tabular}{|c|c|c|c|}
\hline Company & Variant of concern & $\begin{array}{l}\text { Neutralization } \\
\text { by pseudovirion } \\
\text { or live viral } \\
\text { plaque assay }\end{array}$ & References \\
\hline Moderna & $\begin{array}{l}\text { B.1.1.7 }(\alpha) \\
\text { P.1 }(\gamma) \\
\text { B.1.351 }(\beta) \\
\text { B.1.617.2 }(\delta)\end{array}$ & $\begin{array}{l}\text { Decrease by } 1.8 \mathrm{x} \\
\text { Decrease by } 4.5 \mathrm{x} \\
\text { Decrease by } \leq 8.6 \mathrm{x} \\
\text { Not reported }\end{array}$ & $\begin{array}{l}{[23]} \\
{[23]} \\
{[23]} \\
\mathrm{n} / \mathrm{a}\end{array}$ \\
\hline Pfizer & $\begin{array}{l}\text { B.1.1.7 }(\alpha) \\
\text { P.1 }(\gamma) \\
\text { B.1.351 }(\beta) \\
\text { B.1.617.2 }(\delta)\end{array}$ & $\begin{array}{l}\text { Decrease by } 2 \mathrm{x} \\
\text { Decrease by } 6.7 \mathrm{x} \\
\text { Decrease by } \leq 6.5 \mathrm{x} \\
\text { Not reported }\end{array}$ & $\begin{array}{l}{[23]} \\
{[32]} \\
{[23]} \\
\mathrm{n} / \mathrm{a}\end{array}$ \\
\hline Johnson \& Johnson & $\begin{array}{l}\text { B.1.1.7 }(\alpha) \\
\text { P.1 }(\gamma) \\
\text { B.1.351 }(\beta) \\
\text { B.1.617.2 }(\delta) \\
\end{array}$ & $\begin{array}{l}\text { Not reported } \\
\text { Not reported } \\
\text { Not reported } \\
\text { Not reported } \\
\end{array}$ & $\begin{array}{l}\mathrm{n} / \mathrm{a} \\
\mathrm{n} / \mathrm{a} \\
\mathrm{n} / \mathrm{a} \\
\mathrm{n} / \mathrm{a}\end{array}$ \\
\hline AstraZeneca & $\begin{array}{l}\text { B.1.1.7 }(\alpha) \\
\text { P.1 }(\gamma) \\
\text { B.1.351 }(\beta) \\
\text { B.1.617.2 }(\delta)\end{array}$ & $\begin{array}{l}\text { Decrease by } 9 \mathrm{x} \\
\text { Not reported } \\
\text { Decrease by } \leq 86 \% \\
\text { Not reported }\end{array}$ & $\begin{array}{l}6] \\
\mathrm{n} / \mathrm{a} \\
{[23]} \\
\mathrm{n} / \mathrm{a}\end{array}$ \\
\hline Novavax & $\begin{array}{l}\text { B.1.1.7 }(\alpha) \\
\text { P.1 }(\gamma) \\
\text { B.1.351 }(\beta) \\
\text { B.1.617.2 }(\delta)\end{array}$ & $\begin{array}{l}\text { Decrease by } 1.8 \mathrm{x} \\
\text { Not reported } \\
\text { Not reported } \\
\text { Not reported }\end{array}$ & $\begin{array}{l}{[23]} \\
\mathrm{n} / \mathrm{a} \\
\mathrm{n} / \mathrm{a} \\
\mathrm{n} / \mathrm{a}\end{array}$ \\
\hline Sputnik V & $\begin{array}{l}\text { B.1.1.7 }(\alpha) \\
\text { P.1 }(\gamma) \\
\text { B.1.351 }(\beta) \\
\text { B.1.617.2 }(\delta)\end{array}$ & $\begin{array}{l}\text { Not reported } \\
\text { Not reported } \\
\text { Not reported } \\
\text { Not reported }\end{array}$ & $\begin{array}{l}\mathrm{n} / \mathrm{a} \\
\mathrm{n} / \mathrm{a} \\
\mathrm{n} / \mathrm{a} \\
\mathrm{n} / \mathrm{a}\end{array}$ \\
\hline Sinovac & $\begin{array}{l}\text { B.1.1.7 }(\alpha) \\
\text { P.1 }(\gamma) \\
\text { B.1.351 }(\beta) \\
\text { B.1.617.2 }(\delta)\end{array}$ & $\begin{array}{l}\text { Not reported } \\
\text { Not reported } \\
\text { Not reported } \\
\text { Not reported }\end{array}$ & $\begin{array}{l}\mathrm{n} / \mathrm{a} \\
\mathrm{n} / \mathrm{a} \\
\mathrm{n} / \mathrm{a} \\
\mathrm{n} / \mathrm{a}\end{array}$ \\
\hline Sinopharm & $\begin{array}{l}\text { B.1.1.7 }(\alpha) \\
\text { P.1 }(\gamma) \\
\text { B.1.351 }(\beta) \\
\text { B.1.617.2 }(\delta)\end{array}$ & $\begin{array}{l}\text { Not reported } \\
\text { Not reported } \\
\text { Not reported } \\
\text { Not reported }\end{array}$ & $\begin{array}{l}\mathrm{n} / \mathrm{a} \\
\mathrm{n} / \mathrm{a} \\
\mathrm{n} / \mathrm{a} \\
\mathrm{n} / \mathrm{a}\end{array}$ \\
\hline
\end{tabular}


medRxiv preprint doi: https://doi.org/10.1101/2021.05.20.21257461; this version posted June 18, 2021. The copyright holder for this preprint (which was not certified by peer review) is the author/funder, who has granted medRxiv a license to display the preprint in perpetuity.

It is made available under a CC-BY 4.0 International license.

\section{References}

[1] Halloran ME, Longini IM, Struchiner CJ. Design and Analysis of Vaccine Studies. Springer; 2010.

[2] Viechtbauer W. Conducting Meta-Analyses in $\mathrm{R}$ with the metafor Package. Journal of Statistical Software, Articles. 2010;36(3):1-48. Available from: https://www . jstatsoft.org/v036/i03.

[3] R Core Team. R: a language and environment for statistical computing;. Available from: https://www.gbif.org/tool/81287/r-a-language-and-environmentfor-statistical-computing.

[4] ModernaTX; 2020. Available from: https://www.fda.gov/media/144434/download.

[5] Pfizer; 2020. Available from: https://www.fda.gov/media/144246/download.

[6] Emary KR, Golubchik T, Aley PK, Ariani CV, Angus BJ, Bibi S, et al. Efficacy of ChAdOx1 nCoV-19 (AZD1222) vaccine against SARS-CoV-2 VOC 202012/01 (B. 1.1. 7). The Lancet. 2021.

[7] Vizient; 2021. Available from: https://www.vizientinc.com/-/media/documents/ sitecorepublishingdocuments/public/covid19_sidebyside_vaccinecompare. pdf.

[8] Supply Vaccines to Eliminate Human Diseases;. Available from: http://www. sinovacbio. com/news/shownews . php? id=1154\&amp; lang=en.

[9] Evidence Assessment: Sinopharm/bbibp Covid-19 Vaccine. Sage Working Group;. Available from: https://cdn.who.int/media/docs/defaultsource/immunization/sage/2021/april/2_sage29apr2021_critical-evidence_ sinopharm.pdf.

[10] Dagan N, Barda N, Kepten E, Miron O, Perchik S, Katz MA, et al. BNT162b2 mRNA Covid-19 vaccine in a nationwide mass vaccination setting. New England Journal of Medicine. 2021.

[11] Janssen Biotech, Inc; 2021. Available from: https://www.fda.gov/media/146217/ download.

[12] Sadoff J, Gray G, Vandebosch A, Cárdenas V, Shukarev G, Grinsztejn B, et al. Safety and Efficacy of Single-Dose Ad26. COV2. S Vaccine against Covid-19. New England Journal of Medicine. 2021.

[13] Novavax Confirms High Levels of Efficacy Against Original and Variant COVID19 Strains in United Kingdom and South Africa Trials;. Available from: https://ir.novavax.com/news-releases/news-release-details/novavaxconfirms-high-levels-efficacy-against-original-and. 
medRxiv preprint doi: https://doi.org/10.1101/2021.05.20.21257461; this version posted June 18, 2021. The copyright holder for this preprint (which was not certified by peer review) is the author/funder, who has granted medRxiv a license to display the preprint in perpetuity.

It is made available under a CC-BY 4.0 International license.

[14] Jones I, Roy P. Sputnik V COVID-19 vaccine candidate appears safe and effective. The Lancet. 2021;397(10275):642-643.

[15] COVID-19 Vaccine AstraZeneca confirms 100\% protection against severe disease, hospitalisation and death in the primary analysis of Phase III trials; 2021. Available from: https://www.astrazeneca.com/media-centre/pressreleases/2021/covid-19-vaccine-astrazeneca-confirms-protection-againstsevere-disease-hospitalisation-and-death-in-the-primary-analysis-ofphase-iii-trials.html.

[16] Logunov DY, Dolzhikova IV, Shcheblyakov DV, Tukhvatulin AI, Zubkova OV, Dzharullaeva AS, et al. Safety and efficacy of an rAd26 and rAd5 vector-based heterologous prime-boost COVID-19 vaccine: an interim analysis of a randomised controlled phase 3 trial in Russia. The Lancet. 2021;397(10275):671-681.

[17] GRADE: Moderna COVID-19 Vaccine. Centers for Disease Control and Prevention; 2020. Available from: https://www.cdc.gov/vaccines/acip/recs/grade/covid19-moderna-vaccine.html.

[18] Vasileiou E, Simpson CR, Shi T, Kerr S, Agrawal U, Akbari A, et al. Interim findings from first-dose mass COVID-19 vaccination roll-out and COVID-19 hospital admissions in Scotland: a national prospective cohort study. The Lancet. 2021.

[19] Interim Estimates of Vaccine Effectiveness of BNT162b2 and mRNA-1273 COVID-19 Vaccines in Preventing SARS-CoV-2 Infection Among Health Care Personnel, First Responders, and Other Essential and Frontline Workers - Eight U.S. Locations, December 2020-March 2021. Centers for Disease Control and Prevention; 2021. Available from: https : //www.cdc.gov/mmwr/volumes/70/wr/mm7013e3.htm.

[20] Hall VJ, Foulkes S, Saei A, Andrews N, Oguti B, Charlett A, et al. COVID-19 vaccine coverage in health-care workers in England and effectiveness of BNT162b2 mRNA vaccine against infection (SIREN): a prospective, multicentre, cohort study. The Lancet. 2021.

[21] K; CGLTSTAD. Assessment of Effectiveness of 1 Dose of BNT162b2 Vaccine for SARSCoV-2 Infection 13 to 24 Days After Immunization. U.S. National Library of Medicine;. Available from: https://pubmed.ncbi.nlm.nih.gov/34097044/.

[22] Harris RJ, Hall JA, Zaidi A, Andrews NJ, Dunbar JK, Dabrera G. Impact of vaccination on household transmission of SARS-COV-2 in England. medRxiv. 2021.

[23] Abdool Karim SS, de Oliveira T. New SARS-CoV-2 Variants - Clinical, Public Health, and Vaccine Implications. New England Journal of Medicine. Available from: https: //doi.org/10.1056/NEJMc2100362.

[24] Abu-Raddad LJ, Chemaitelly H, Butt AA. Effectiveness of the BNT162b2 Covid-19 Vaccine against the B.1.1.7 and B.1.351 Variants. New England Journal of Medicine. Available from: https://doi.org/10.1056/NEJMc2104974. 
medRxiv preprint doi: https://doi.org/10.1101/2021.05.20.21257461; this version posted June 18, 2021. The copyright holder for this preprint (which was not certified by peer review) is the author/funder, who has granted medRxiv a license to display the preprint in perpetuity.

It is made available under a CC-BY 4.0 International license.

[25] Bernal JL, Andrews N, Gower C, Gallagher E, Simmons R, Thelwall S, et al. Effectiveness of COVID-19 vaccines against the B.1.617.2 variant. medRxiv. 2021. Available from: https://www.medrxiv.org/content/early/2021/05/24/2021.05. 22.21257658 .

[26] Stieg C. How the different Covid vaccines will handle new variants of the virus. CNBC; 2021. Available from: https://www.cnbc.com/2021/03/05/how-the-differentcovid-vaccines-will-handle-variants.html\#: : text=If $\% 20 \mathrm{a} \% 20$ fully $\%$ 20vaccinated $\% 20$ person, as $\% 20$ Moderna's\%20 original $\% 20$ Covid $\% 20$ vaccine.

[27] Collier DA, De Marco A, Ferreira IA, Meng B, Datir R, Walls AC, et al. Sensitivity of SARS-CoV-2 B. 1.1. 7 to mRNA vaccine-elicited antibodies. Nature. 2021:1-8.

[28] Wu K, Werner AP, Koch M, Choi A, Narayanan E, Stewart-Jones GB, et al. Serum Neutralizing Activity Elicited by mRNA-1273 Vaccine. New England Journal of Medicine. 2021.

[29] Hitchings M, Ranzani OT, Torres MS, de Oliveira SB, Almiron M, Said R, et al. Effectiveness of CoronaVac in the setting of high SARS-CoV-2 P. 1 variant transmission in Brazil: A test-negative case-control study. medRxiv. 2021.

[30] Madhi SA, Baillie V, Cutland CL, Voysey M, Koen AL, Fairlie L, et al. Efficacy of the ChAdOx1 nCoV-19 Covid-19 Vaccine against the B. 1.351 Variant. New England Journal of Medicine. 2021.

[31] Shinde V, Bhikha S, Hoosain Z, Archary M, Bhorat Q, Fairlie L, et al. Efficacy of NVX-CoV2373 Covid-19 Vaccine against the B.1.351 Variant. New England Journal of Medicine. Available from: https://doi.org/10.1056/NEJMoa2103055.

[32] Science Brief: Background Rationale and Evidence for Public Health Recommendations for Fully Vaccinated People. Centers for Disease Control and Prevention;. Available from: https://www.cdc.gov/coronavirus/2019-ncov/science/sciencebriefs/fully-vaccinated-people.html\#ref 4. 